\title{
An Experimental Study on Evaluation of Compressive Strength in Cement Mortar Using Averaged Electromagnetic Properties
}

\author{
Seung-Jun Kwon, ${ }^{1)}$ Maria, Q. Feng, ${ }^{2)}$ Tae-Won Park, ${ }^{3)}$ and Ung-Jin $\mathrm{Na}^{4)}$
}

(Received June 12, 2008, Revised March 30, 2009, Accepted April 30, 2009)

\begin{abstract}
A non-destructive testing (NDT) method for evaluating physical properties of concrete including the compressive strength is highly desirable. This paper presents such an NDT method based on measurement of electromagnetic (EM) properties of the material. Experiments are carried out on cement mortar with different water/cement (W/C) ratios. Their EM properties including the conductivity and the dielectric constant are measured at different exposure conditions and curing periods over a wide frequency range of the EM wave. The compressive strength of these specimens is also tested. It is found that both the conductivity and the dielectric constant increase as the $\mathrm{W} / \mathrm{C}$ ratio decreases and the curing period increases, which lead strength development in the specimens. A linear correlation is observed between the averaged EM properties over the 5 to $20 \mathrm{GHz}$ frequency range and the measured compressive strength, demonstrating the effectiveness of the EM property-based NDT method in evaluating strength of OPC mortar.
\end{abstract}

Keywords: NDT, electromagnetic, cement mortar, conductivity, dielectric constant.

\section{Introduction}

An NDT technique is highly desirable for evaluating strength and condition of cement-based construction materials. Among the potential techniques, EM property-based NDT methods have been studied for these materials. ${ }^{1-4}$ The pore and saturation in a porous media such as concrete and cement mortar are considered as major parameters effecting their EM properties. The saturation of concrete is reported to have the most significant contribution toward the complex dielectric permittivity of the overall mixture. $^{2-4}$ In addition, the pores in the cement matrix also play an important role in the electrical conductivity spectra. ${ }^{3,5}$ The pore and saturation are major parameters affecting not only the EM properties, but also physical properties in cementbased materials. During the hydration process in cement particles, pores occur in the concrete and the amount of pore (porosity) is in close relationship with structural performance like strength $^{6-8}$ and durability performance like diffusion ${ }^{9,10}$ and water permeation. $^{11}$

Many studies have been performed on concrete utilizing the

\footnotetext{
${ }^{1)}$ Dept. of Civil \& Environmental Engineering, University of California Irvine, Irvine, CA, 92697, USA. seungjuk@uci.edu

${ }^{2)}$ Dept. of Civil \& Environmental Engineering, University of California Irvine, Irvine, CA, 92697, USA.

${ }^{3)}$ Dept. of Architectural Engineering, Dankook University, Yongin 448-701, Korea.

${ }^{4)}$ Busan Port Construction Office, Ministry of Land, Transport and Maritime Affairs, Busan 601-726, Korea.

Copyright (c) 2009, Korea Concrete Institute. All rights reserved, including the making of copies without the written permission of the copyright proprietors.
}

EM properties. Characterization of EM properties in cementbased materials has been studied and documented. ${ }^{3-5,12-14}$ Some of these studies are focused on permeability and diffusion coefficient for material durability research. ${ }^{15-17}$ Others are for the characterization of EM properties in concrete using mineral admixtures such as FA (fly ash) and GGBS (ground granulated blast-furnace slag) considering concrete curing stage. ${ }^{18-21}$ In addition, EM properties are applied for monitoring and condition assessment of reinforced concrete structures. They include monitoring of deteriorated concrete ${ }^{13,22-24}$ and modeling of EM properties in porous concrete or cement-based system. ${ }^{2,23-25}$ Recently, EM properties are used to assess condition of FRP-wrapped concrete structures. $^{26-30}$

Despite these research activities, very limited investigations have been performed on relationships between the EM properties and physical properties (such as compressive strength) of cement-based construction materials. The ultimate goal of this study is to investigate the relationship between the EM properties and the compressive strength of concrete. In order to avoid the effect of coarse aggregates, OPC mortar is first studied. OPC mortar specimens are prepared with five different $\mathrm{W} / \mathrm{C}$ ratios $(40 \%, 45 \%, 50 \%, 55 \%$, and $60 \%)$ and the compressive strength is measured at the age of 1,2 , and 4 weeks curing. Meanwhile the EM properties of these specimens including the conductivity and the dielectric constant are measured using EM waves over a wide frequency range from 0.2 through $20 \mathrm{GHz}$. Furthermore, the specimens are tested not only in room conditions but also in saturated conditions in order to study the effect of the saturation on EM properties. Based on the experimental study, the relationship between the EM properties and physical characteristics of OPC mortar is obtained and discussed. 


\section{Conductivity and dielectric constant}

Every material has a unique set of EM properties. Dielectric materials such as concrete can be characterized by two independent electromagnetic properties: the complex permittivity $\left(\varepsilon^{*}\right)$ and the complex permeability $\left.\left(\mu^{*}\right)\right)^{3}$ In general, four independent measurements are necessary to obtain the real and imaginary parts of $\varepsilon^{*}$ and $\mu^{*}$. However, most common dielectric materials including concrete are nonmagnetic, making the permeability $\mu^{*}$ close to the permeability of free space $\left(\mu_{0}=4 \pi \times 10^{-7}\right.$ Henry/ meter). Thus, the focus of the discussion is on the complex permeability $\varepsilon^{*}$ which is defined in references. ${ }^{3,29}$

$$
\varepsilon^{*}=\varepsilon^{\prime}-j \varepsilon^{\prime \prime}
$$

where, $\varepsilon^{\prime}$ and $\varepsilon^{\prime \prime}$ are the real and imaginary parts of the complex permittivity with $j=\sqrt{-1}$.

Dividing Eq. (1) by the permittivity in free space $\varepsilon_{0}\left(8.854 \times 10^{-12}\right.$ Farad/m), Eq. (2) and furthermore Eq. (3) can be derived. ${ }^{3,29}$

$$
\begin{gathered}
\frac{\varepsilon^{*}}{\varepsilon_{0}}=\frac{\varepsilon^{\prime}}{\varepsilon_{0}}-j \frac{\varepsilon^{\prime \prime}}{\varepsilon_{0}} \\
\varepsilon_{r}^{*}=\varepsilon_{r}^{\prime}-j \varepsilon_{r}^{\prime \prime}
\end{gathered}
$$

where, $\varepsilon_{r}^{*}$ is the relative complex permittivity, and $\varepsilon_{r}^{\prime}$ and $\varepsilon_{r}^{\prime \prime}$ are its real and imaginary parts, respectively. The real part of the relative complex permittivity, so-called dielectric constant $\left(\varepsilon_{r}^{\prime}>1\right)$, means how much energy from an external electric field is stored in a material. The imaginary part of the relative complex permittivity, $\left(\varepsilon_{r}^{\prime \prime}>0\right)$, shows how dissipative the material is to an external electric field, which is simply referred to as the loss factor. ${ }^{3,22}$ The equivalent conductivity can be expressed in terms of the imaginary part of the complex permittivity $\left(\varepsilon^{\prime \prime}\right)$ as shown in Eq. (4).

$$
\sigma=\varepsilon^{\prime \prime} \omega=\left(\varepsilon_{r}^{\prime} \varepsilon_{0} \tan \delta\right) 2 \pi f
$$

where, $\sigma$ is conductivity ( $\mathrm{mhos} / \mathrm{m}), \omega$ is the EM wave frequency ( $\mathrm{rad} / \mathrm{sec}), \tan \delta$ is loss tangent (the ratio of energy loss to energy stored in a material) and $f$ is frequency in (Hz). These EM properties are not constant and dependent upon frequency, temperature, moisture content, chloride content, and concrete mix constituents. ${ }^{2-4}$ In this study, two EM properties of the OPC mortar, the dielectric constant and the conductivity are measured in a given EM wave frequency.

\section{Test of EM properties and compressive strength in OPC mortar}

OPC motor specimens with different $\mathrm{W} / \mathrm{C}$ ratios are made and their strengths are tested at different curing periods and exposure conditions. Meanwhile, their EM properties are also measured.

\subsection{Test specimens}

The specimens were made with OPC mortar under five W/C ratios $(40 \%, 45 \%, 50 \%, 55 \%$, and $60 \%)$. Each specimen was kept in an air-curing condition for 3 days after mixing and then in submerged condition $\left(20^{\circ} \mathrm{C}\right)$ for four weeks. The mix proportions and physical properties of aggregate are listed in Table 1.

The cylindrical specimens $(100 \mathrm{~mm} \times 200 \mathrm{~mm})$ are made for the compressive strength tests and rectangular ones $(80 \mathrm{~mm} \times$ $150 \mathrm{~mm} \times 40 \mathrm{~mm}$ ) are also made for measurement of EM properties. The depth of the specimens for EM measurement is determined to be $40 \mathrm{~mm}$, which is considered sufficient to prevent the wave penetrating through the specimen and reflected from the outer boundary. This is based on a previous study that EM measurement of concrete specimens with a depth of $5 \mathrm{~mm}$ suffered slight interference of reflected microwave. ${ }^{14}$

\subsection{EM measurement setup and calibration}

Measurement setup consists of a dielectric probe kit including the analyzing software and an open ended coaxial probe, a network analyzer, and a laptop computer, as shown in Fig. 1. The probe is a cut-off section of transmission line and the EM properties of the material are measured by placing the probe in contact with a flat face of a solid material or immersing into a liquid. The network analyzer is connected with the laptop computer and communicated with and controlled by the laptop computer. ${ }^{29}$ The network analyzer sends and receives the microwave through the probe over a frequency range from $0.2 \mathrm{GHz}$ to $20 \mathrm{GHz}$ at an interval of $0.4 \mathrm{GHz}$. The measured reflection signals are then analyzed by the software at the laptop computer for obtaining the EM properties (i.e., the dielectric constant and the conductivity). Fig. 1(a), (b), and (c) show schematic diagram, picture of measurement setup, and photo measurement, respectively.

Generally for the calibration of the experimental system using the open-ended coaxial probe, well-known properties are needed over the measuring frequency range. ${ }^{31}$ In this study, calibration was performed on air and water in $25^{\circ} \mathrm{C}$ temperature prior to the measurement. The calibration results, in terms of the dielectric constant and the conductivity, are shown in Fig. 2, well agreeing with those reported in literature. ${ }^{3,29}$

\subsection{Tests for compressive strength and EM properties}

Three cylindrical OPC mortar specimens are prepared for each compressive strength test. The compressive tests of the specimens with five different $\mathrm{W} / \mathrm{C}$ ratios are performed at the age of one, two, and four weeks, based on the testing standard. ${ }^{32}$ The specimens for EM properties are kept in the same conditions as those for compressive strength tests. Grinding with 3 $5 \mathrm{~mm}$ depth is performed for removal of bleeding portion and

Table 1 Mixture proportions and properties of sand for specimens.

\begin{tabular}{c|c|c|c}
\hline W/C ratio (\%) & $\begin{array}{c}\text { Cement } \\
(\mathrm{kg} / 25 \text { liter })\end{array}$ & $\begin{array}{c}\text { Sand } \\
(\mathrm{kg} / 25 \mathrm{liter})\end{array}$ & $\begin{array}{c}\text { Water } \\
(\mathrm{kg} / 25 \mathrm{liter})\end{array}$ \\
\hline \hline 40 & 8.50 & 25.00 & 3.40 \\
\hline 45 & 8.50 & 25.00 & 3.83 \\
\hline 50 & 8.50 & 25.00 & 4.25 \\
\hline 55 & 8.50 & 25.00 & 4.68 \\
\hline 60 & 8.50 & 25.00 & 5.10 \\
\hline
\end{tabular}

- Cement : Sand = $1: 3.125$ (weight ratio)

- Physical properties of aggregate

Specific gravity $\left(=2.60 \mathrm{~g} / \mathrm{cm}^{3}\right)$, Absorption $(=0.95 \%)$, F.M. $(=2.64)$ 


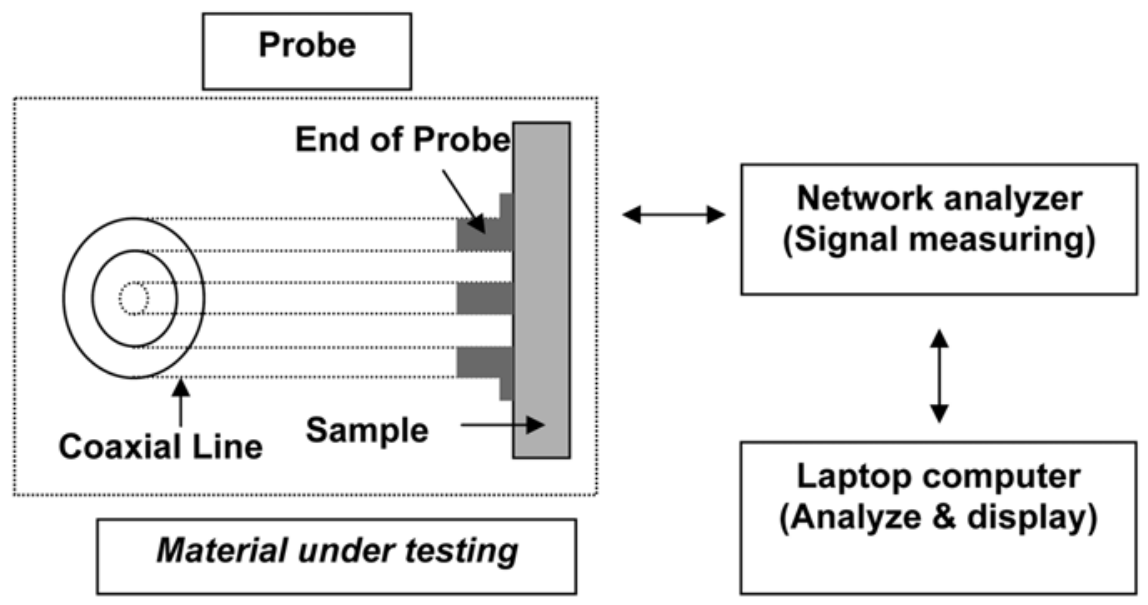

(a) Schematic diagram

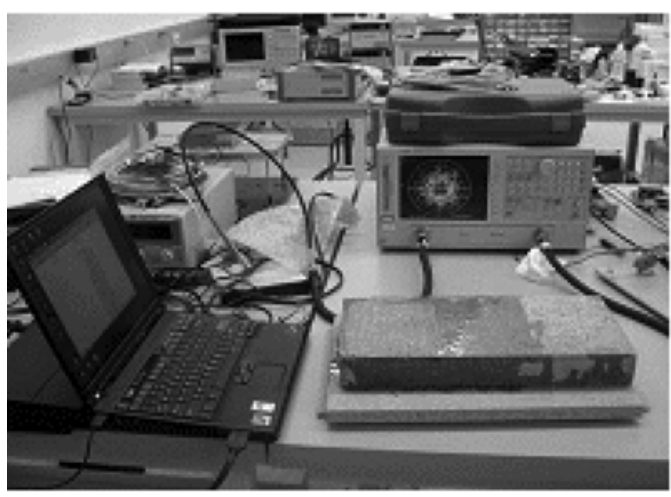

(b) Measurement setup

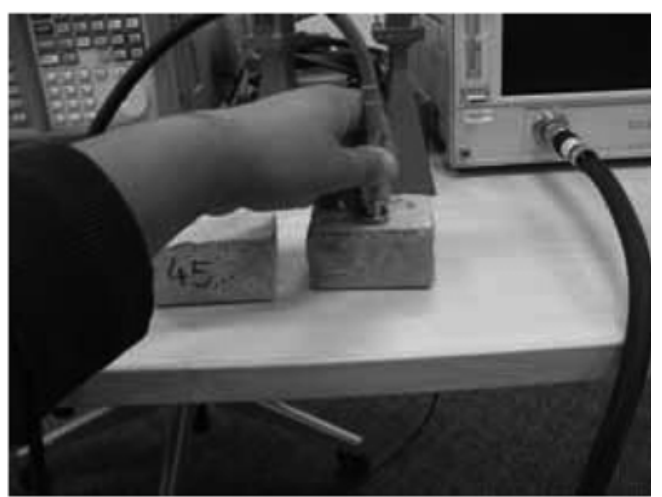

(c) Measurement for sample

Fig. 1 Schematic diagram and EM measurement setup.

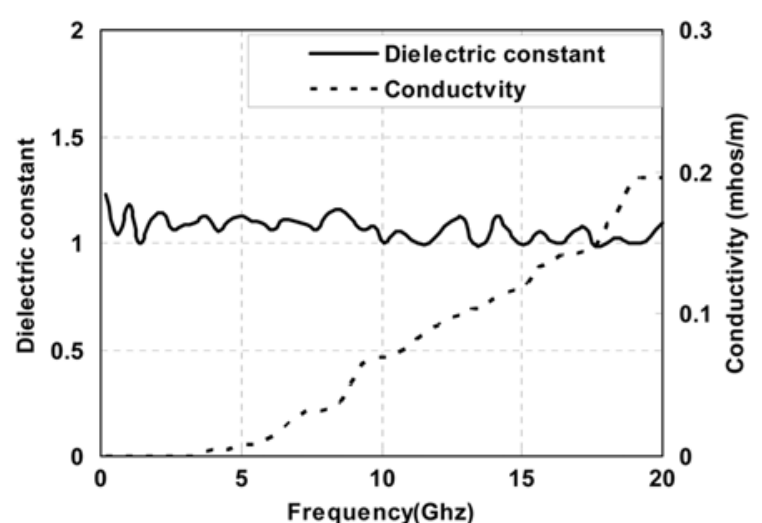

(a) Calibration using air $\left(25^{\circ} \mathrm{C}\right)$

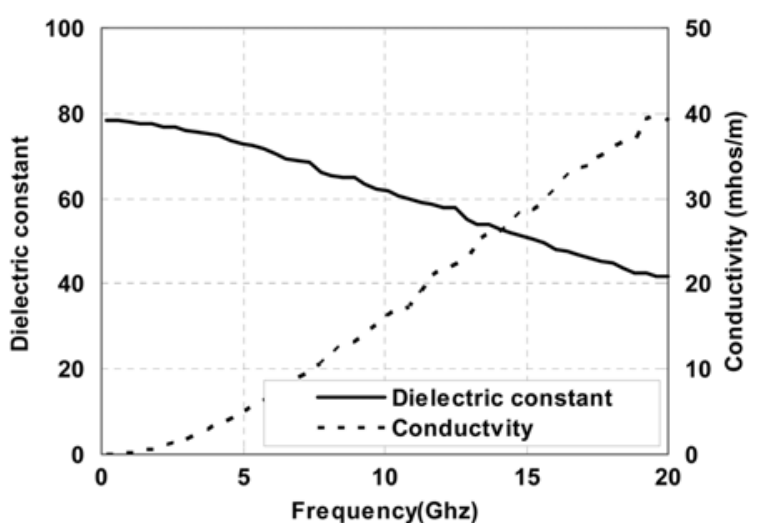

(b) Calibration using water $\left(25^{\circ} \mathrm{C}\right)$

Fig. 2 Results of calibration.

unevenness of the surface. For using the averaged value within the range of $0.2 \sim 20 \mathrm{GHz}$, EM properties are measured 10 times for each specimen. Before measurement of the EM properties, some of the specimens are exposed to room condition (temperature: $20 \sim 22^{\circ} \mathrm{C}$; relative humidity: $55 \sim 62 \%$ ) for 36 hours, while the others are immediately tested after bring them out of water in order to evaluate the changed EM properties due to saturation. The test plan and exposure conditions are summarized in Table 2.

\section{Measured strengths and EM properties}

\subsection{Compressive strengths with different W/C ratios}

The results of the compressive test show the traditional trend of strength development that the strength increases with reduced W/C ratios and extended curing periods. Through extension of the curing period in early age (within 28 days) and decrease in $\mathrm{W} / \mathrm{C}$ ratio, cement-based material has less porosity and more hydrates due to the sufficient hydration process, which is in close relation with the compressive strength. ${ }^{7,8,33,34}$ The results of 
Table 2 Test plan and exposure conditions.

\begin{tabular}{c|c|c|c}
\hline \multirow{2}{*}{\begin{tabular}{c}
\multirow{2}{*}{$\begin{array}{l}\text { W/C } \\
(\%)\end{array}$} \\
\cline { 2 - 4 }
\end{tabular}} & $\begin{array}{c}\text { Compressive strength } \\
(\phi 100 \mathrm{~mm} \times 200 \mathrm{~mm})\end{array}$ & \multicolumn{2}{c}{$\begin{array}{c}\text { EM properties } \\
(100 \mathrm{~mm} \times 150 \mathrm{~mm} \times 40 \mathrm{~mm})\end{array}$} \\
\cline { 2 - 4 } & \multicolumn{3}{|c}{ Number of specimens } \\
\cline { 2 - 4 } & Room condition & Saturated condition & Room condition \\
\hline \hline 40 & 3 & 2 & 2 \\
\hline 45 & 3 & 2 & 2 \\
\hline 50 & 3 & 2 & 2 \\
\hline 55 & 3 & 2 & 2 \\
\hline 60 & 3 & 2 & 2 \\
\hline
\end{tabular}

- Room condition: temperature $\left(22 \sim 25^{\circ} \mathrm{C}\right)$, relative humidity $(50 \sim 62 \%)$

compressive strength measured from the compressive testing of the cylindrical samples are shown in Fig. 3, in which (a) shows the compressive strength increases as the curing period extends for different $\mathrm{W} / \mathrm{C}$ ratios and (b) the strength decreases as the W/ $\mathrm{C}$ ratio increases for different curing periods.

\subsection{EM properties with different W/C ratios and curing periods}

\subsubsection{EM properties with different $\mathrm{W} / \mathrm{C}$ ratios}

The conductivity and dielectric constant measured after four weeks of curing under different exposure conditions are plotted in Fig. 4 over a large range of EM wave frequencies. From Fig. 4 , the conductivity increases and the dielectric constant decreases in all the cases with increasing frequency, regardless of $\mathrm{W} / \mathrm{C}$

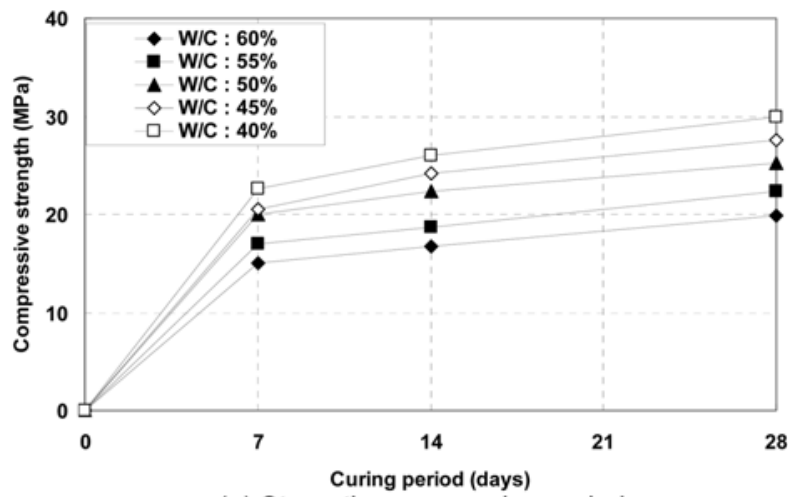

(a) Strength versus curing period

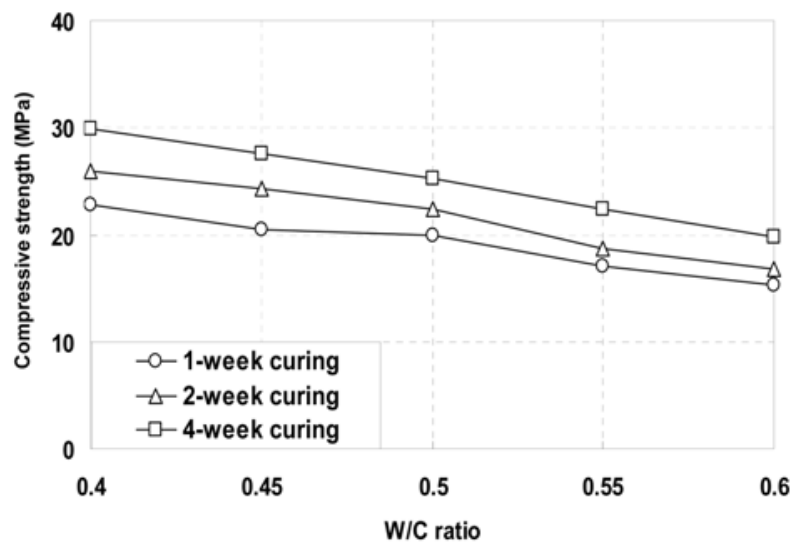

(b) Strength versus W/C ratios

Fig. 3 Test results of compressive strength in OPC mortar.

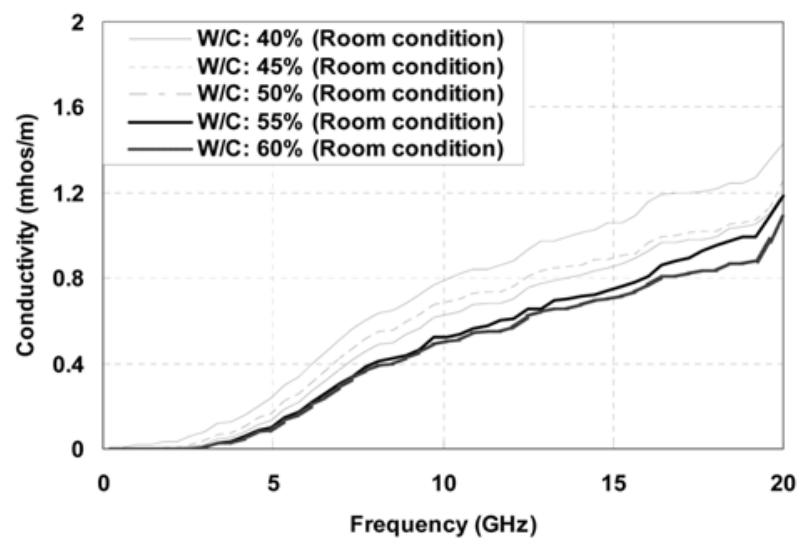

(a) Conductivity in room condition

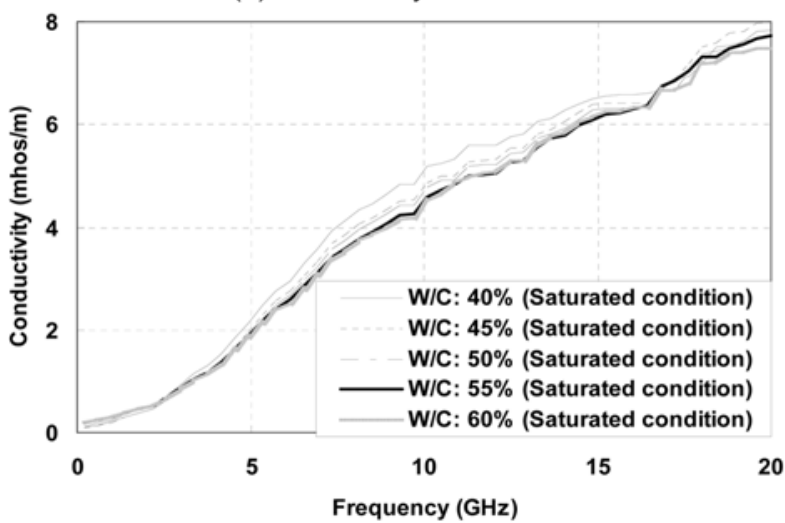

(b) Conductivity in saturated condition

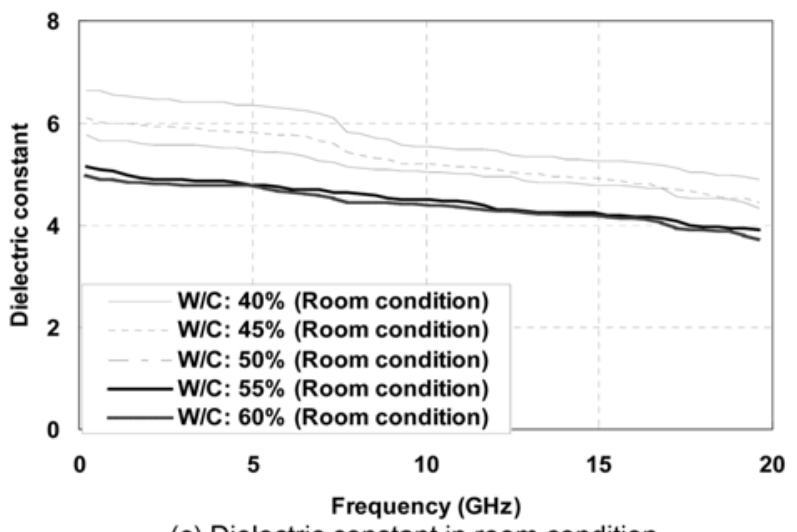

(c) Dielectric constant in room condition

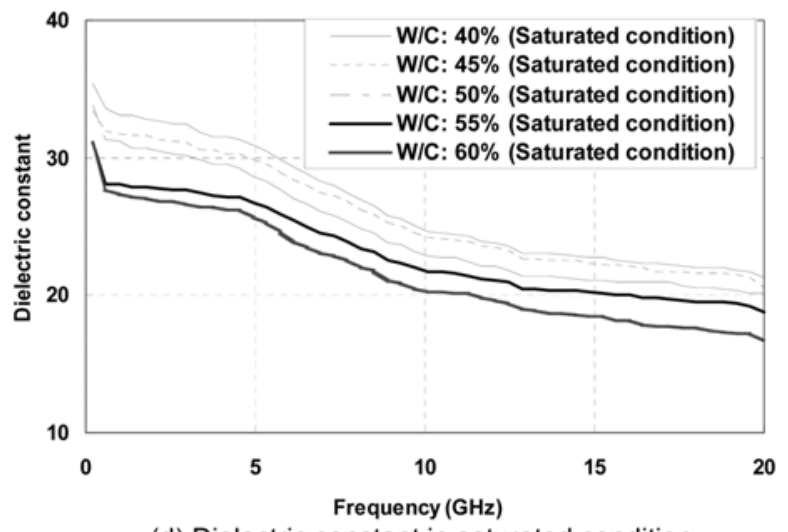

(d) Dielectric constant in saturated condition

Fig. 4 EM properties measured in different exposure conditions.

ratios. In a given frequency, the conductivity and the dielectric constant measured on the specimens with lower W/C ratios show higher values. This trend is based on characteristics of 
nonmetallic material and consistent with results of previous study in dried conditions. ${ }^{29}$

\subsubsection{EM properties with different curing periods}

To facilitate a comparison of EM properties with different W/ $\mathrm{C}$ ratios in a specific curing period, averages are taken respectively for the conductivity and the dielectric constant values measured over the 5 20 GHz frequency range. In Fig. 5, the averaged EM property values normalized to the maximum value (under $40 \% \mathrm{~W} / \mathrm{C}$ ratio) are plotted for one, two, and four weekcuring periods, respectively. In the given curing period, the averaged dielectric constant and conductivity increase as the W/C ratios reduce.

For the specimens in the room condition, change in the W/C ratio from 0.4 to 0.6 significantly reduces the EM properties.

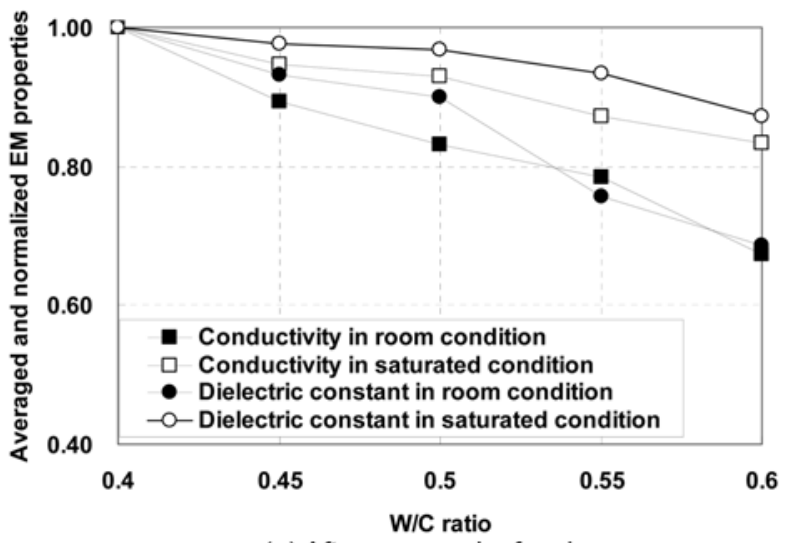

(a) After one week of curing

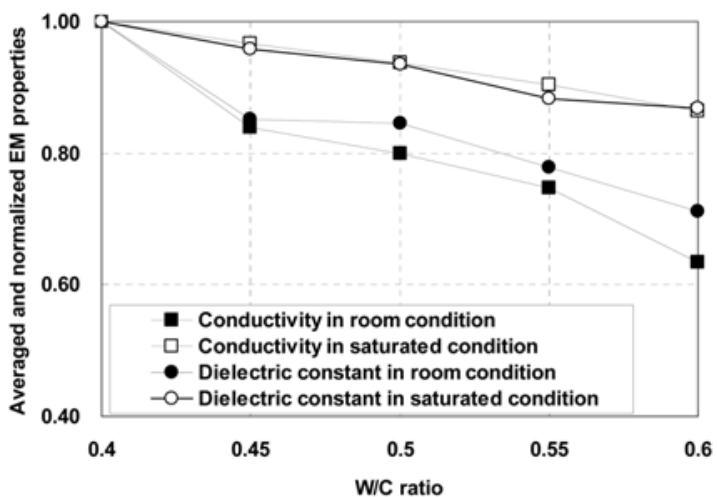

(b) After two weeks of curing

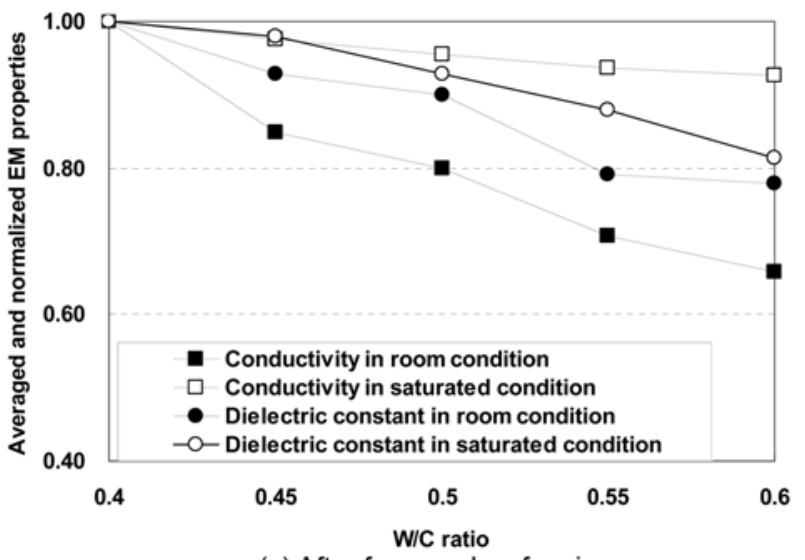

(c) After four weeks of curing

Fig. 5 Averaged and normalized EM properties for different curing periods.
More specifically, the conductivity at the $0.6 \mathrm{~W} / \mathrm{C}$ ratio is $67 \sim 63 \%$ of the value at the $0.4 \mathrm{~W} / \mathrm{C}$ ratio, while dielectric constant is $78 \sim 69 \%$. In the saturated condition, however, no significant reduction in the EM properties with increased $\mathrm{W} / \mathrm{C}$ ratios is observed. More specifically, the conductivity at the $0.6 \mathrm{~W} / \mathrm{C}$ ratio is $83 \sim 93 \%$ of the value at $0.4 \mathrm{~W} / \mathrm{C}$ ratio, while the dielectric constant is $87 \sim 81 \%$. This is because water in the fully saturated specimens is a more dominant parameter for the EM properties than the other mix parameters such as the $\mathrm{W} / \mathrm{C}$ ratio. The change in the conductivity and the dielectric constant is respectively plotted in Figs. 6 and 7 with different W/C ratios and curing periods.

For the comparison among different curing periods and W/C ratios, all the measured EM property values are normalized by the maximum value that is measured at the $0.4 \mathrm{~W} / \mathrm{C}$ ratio after four week of curing. These normalized EM property values are plotted in Figs. 8 and 9 and summarized in Table 3. The graphs in Figs. 8 and 9 show a more distinct reduction of the EM property values with the increase in the $\mathrm{W} / \mathrm{C}$ ratio and the decrease in the curing period under the room condition, in comparison to the saturated condition among all the specimens, the minimum EM values are measured in the case of the $0.6 \mathrm{~W} / \mathrm{C}$ ratio after 1 week of curing, they are $48.73 \%$ (conductivity) and $55.01 \%$ (dielectric constant) to the maximum value that are measured in the case of the $0.4 \mathrm{~W} / \mathrm{C}$ ratio after 4 weeks of curing.

\subsection{Relationship between compressive strength and measured EM properties}

Comparing the compressive testing results in Table 3 with the EM property measurement results under different $\mathrm{W} / \mathrm{C}$ ratios

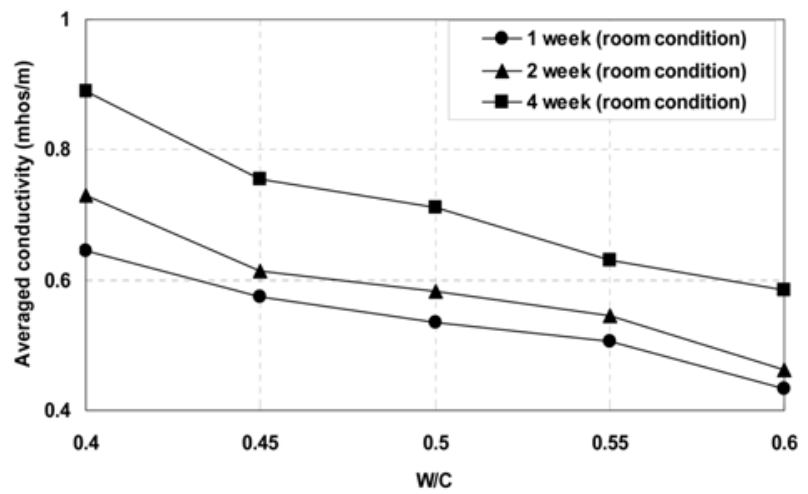

(a) Room condition

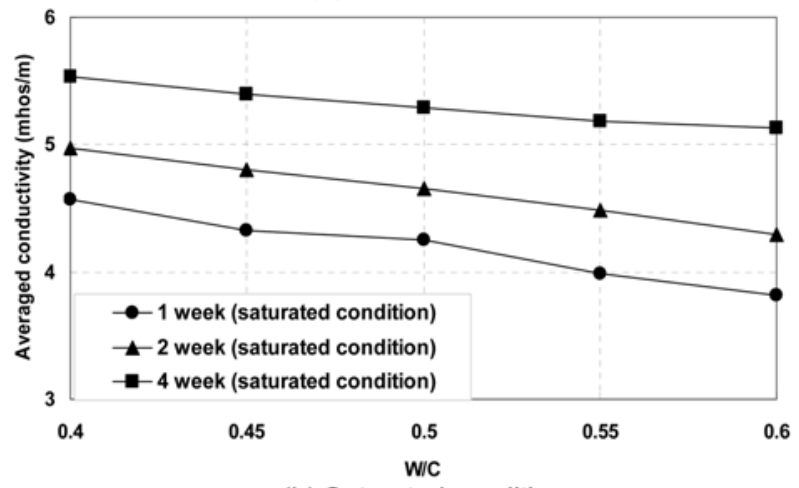

(b) Saturated condition

Fig. 6 Change in conductivity with different W/C ratios and exposure conditions. 


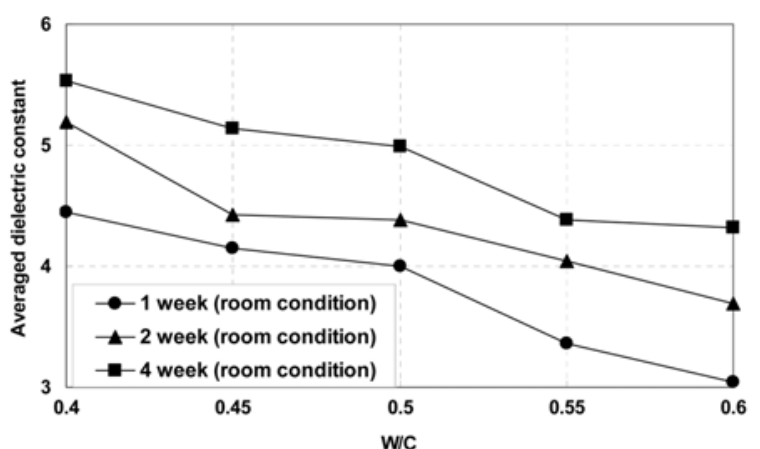

(a) Room condition

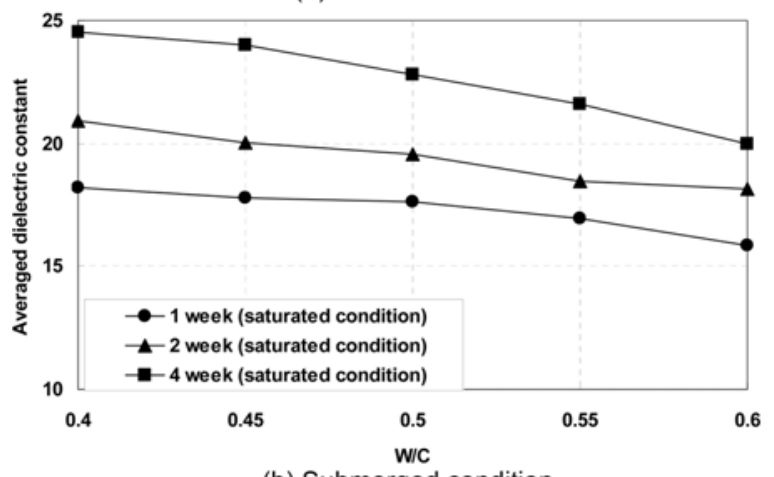

(b) Submerged condition

Fig. 7 Change in dielectric constant with different W/C ratios and exposure conditions.

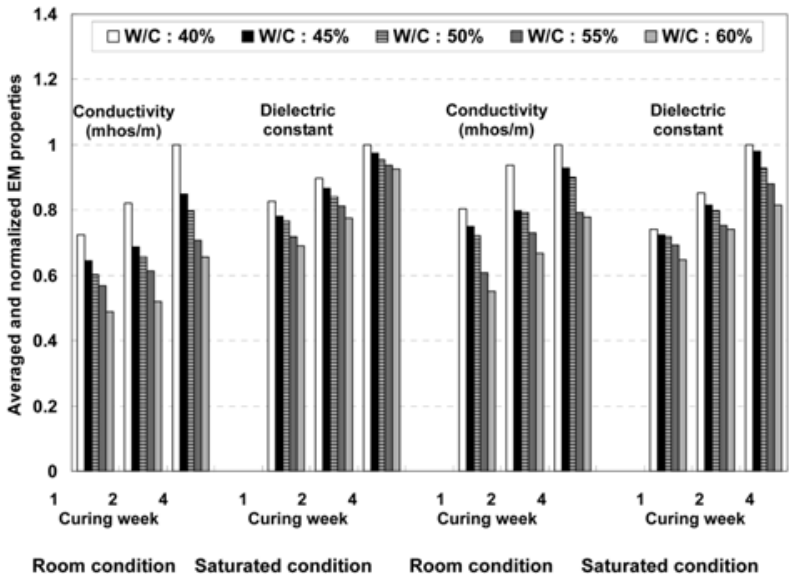

Fig. 8 Comparison of normalized conductivity dielectric constant.

and curing periods, a clear correlation is observed. Linear regression analysis is carried out to obtain the relationship between the compressive strength and the averaged EM properties (over the frequency range of $5 \mathrm{GHz}$ through $20 \mathrm{GHz}$ ). The regression

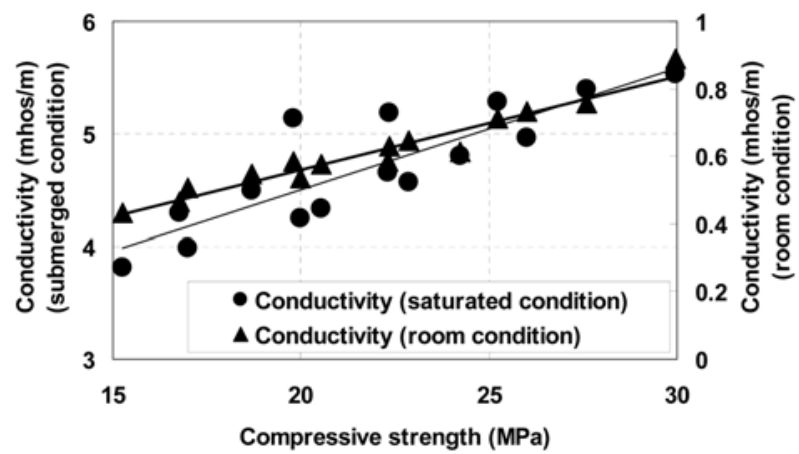

Fig. 9 Relationship between compressive strength and conductivity.

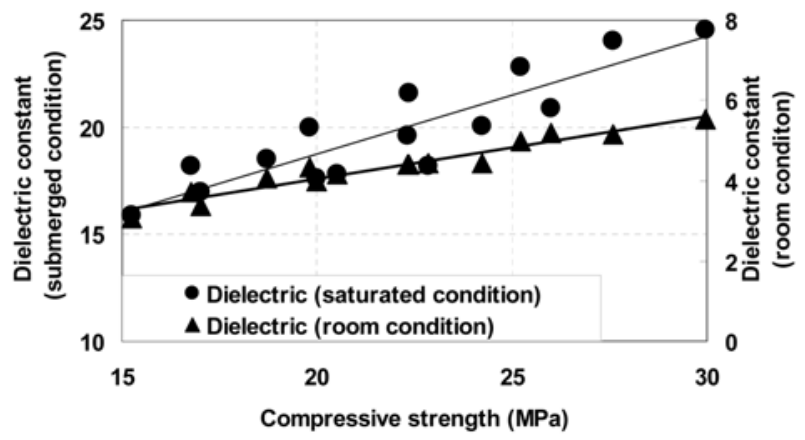

Fig. 10 Relationship between compressive strength and dielectric constant.

results, together with the testing results of the compressive strengths and the measured results of the conductivity and the dielectric constant, are shown in Figs. 9 and 10 for the room and the saturated conditions. The linear relationship and correlation factors are expressed in Eqs. (5) (8).

$$
\begin{aligned}
& C_{\text {sat }}=0.1083 \cdot S+2.3401, \quad R^{2}=0.7422 \\
& C_{\text {room }}=0.0278 \cdot S+0.0053, \quad R^{2}=0.9401 \\
& D_{\text {sat }}=0.5502 \cdot S+7.7156, \quad R^{2}=0.8011
\end{aligned}
$$$$
D_{\text {room }}=0.1074 \cdot S+0.8932, R^{2}=0.9355
$$

where $C$ and $D$ are averaged conductivity and dielectric constant over the frequency range of $5 \sim 20 \mathrm{GHz}$, respectively; $S$ is the measured compressive strength of OPC mortar (MPa); $\mathrm{R}$ is the

\begin{tabular}{|c|c|c|c|c|c|c|c|c|c|c|c|c|}
\hline \multirow{2}{*}{$\mathrm{W} / \mathrm{C}(\%)$} & \multicolumn{4}{|c|}{1 week (\%) } & \multicolumn{4}{|c|}{2 weeks (\%) } & \multicolumn{4}{|c|}{4 weeks (\%) } \\
\hline & $\mathrm{C} / \mathrm{R}$ & $\mathrm{C} / \mathrm{S}$ & $\mathrm{D} / \mathrm{R}$ & $\mathrm{D} / \mathrm{S}$ & $\mathrm{C} / \mathrm{R}$ & $\mathrm{C} / \mathrm{S}$ & $\mathrm{D} / \mathrm{R}$ & $\mathrm{D} / \mathrm{S}$ & $\mathrm{C} / \mathrm{R}$ & $\mathrm{C} / \mathrm{S}$ & $\mathrm{D} / \mathrm{R}$ & $\mathrm{D} / \mathrm{S}$ \\
\hline 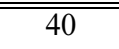 & 72.34 & 82.56 & 80.28 & 74.14 & 82.07 & 89.76 & 93.77 & 85.18 & 100.00 & 100.00 & 100.00 & 100.00 \\
\hline 45 & 64.57 & 78.21 & 74.88 & 72.42 & 68.86 & 86.74 & 79.93 & 81.59 & 84.86 & 97.52 & 92.82 & 97.88 \\
\hline 50 & 60.16 & 76.75 & 72.15 & 71.78 & 65.51 & 84.11 & 79.20 & 79.74 & 79.83 & 95.48 & 90.06 & 92.83 \\
\hline 55 & 56.70 & 71.95 & 60.80 & 69.15 & 61.25 & 81.08 & 73.01 & 75.24 & 70.74 & 93.58 & 79.18 & 88.01 \\
\hline 60 & 48.73 & 68.87 & 55.01 & 64.67 & 52.00 & 77.61 & 66.71 & 73.98 & 65.74 & 92.68 & 77.94 & 81.39 \\
\hline 60 & 48.73 & 68.87 & 55.01 & 64.67 & 52.00 & 77.61 & 66.71 & 73.98 & 65.74 & 92.68 & 77.94 & 81.39 \\
\hline
\end{tabular}
correlation coefficient. The subscripts of sat and room means the

Table 3 Comparison of normalized EM properties.

(Note) C/R : conductivity in room condition, $\mathrm{C} / \mathrm{S}$ : conductivity in submerged condition,

$\mathrm{D} / \mathrm{R}$ : dielectric constant in room condition, $\mathrm{D} / \mathrm{S}$ : dielectric constant in submerged condition. 
saturated and room conditions under which the specimens are tested. In the saturated condition, the measured EM properties are observed to be less correlated because they unsteadily increase in the position of the sample surface which has the large pores filled with local moisture (water). In this paper, over-saturated samples are used for measurement of EM properties, which means abundant water is still on the surface since they are directly tested after pickup form submerged water. If samples with larger pore are saturated, EM properties increase due to the water in pores. However, the results in saturated condition show opposite trends because of the over-saturated condition. The EM behaviors with different saturation are well analyzed in the previous research ${ }^{35}$ which indicates that higher EM properties are measured in mortar with higher $\mathrm{W} / \mathrm{C}$ ratios when they are fully saturated. An increased porosity in mortar with higher W/C ratios can keep more surface water (saturation) which magnifies dielectric constant and conductivities. In the research, ${ }^{35}$ the surface abundant water on sample is removed before measurement for EM properties so that the trends are opposite to the results from this study in saturated condition. From Figs. 9 and 10, it is clearly observed that the both of the EM properties, the conductivity and the dielectric constant, of the OPC mortar increase linearly with the compressive strength. This demonstrates the feasibility of using the non-destructive EM property measurement for evaluating the compressive strength of OPC mortar, and potentially concrete. It is noted that the correlation factors for specimens measured in the room condition are higher than those in the saturated condition.

\section{Conclusions}

Through extensive experiments including the compressive strength tests and EM property measurements of a large number of OPC mortar specimens involving five different $\mathrm{W} / \mathrm{C}$ ratios, three curing periods, and two different exposure conditions (room and saturated), the following conclusions can be made:

1) The measured EM properties, both the conductivity and the dielectric constant, increase with the extension of curing period and reduced $\mathrm{W} / \mathrm{C}$ ratio. The maximum averaged values in the conductivity and the dielectric constant are measured in the specimens with lowest $\mathrm{W} / \mathrm{C}$ ratio of 0.4 and the longest curing period of four weeks.

2) The measured EM properties, both the dielectric constant and the conductivity, clearly show a linear relationship with compressive strength of the OPC mortar under both the room and saturated conditions. This demonstrates a significant potential for non-destructive evaluation of the compressive strength of concrete through the measurement of its EM properties.

3 ) In room condition, the conductivity at the $0.6 \mathrm{~W} / \mathrm{C}$ ratio is $67 \sim 63 \%$ of the value at the $0.4 \mathrm{~W} / \mathrm{C}$ ratio, while dielectric constant is $78 \sim 69 \%$. In the saturated condition, however, no significant reduction in the EM properties with increased $\mathrm{W} / \mathrm{C}$ ratios is observed. The conductivity at the $0.6 \mathrm{~W} / \mathrm{C}$ ratio is $83 \sim 93 \%$ of the value at $0.4 \mathrm{~W} / \mathrm{C}$ ratio, while the dielectric constant is $87 \sim 81 \%$.

4) From the results, it is evaluated that dielectric constant in room condition is most efficient to evaluate the strength of cement mortar, showing higher correlation factor. In the future, the authors will extend this study to concrete specimens considering the influence of the coarse aggregates and its transition zone.

\section{Acknowledgments}

This study was supported by the NaeKyung Engineering Company and the Infra-Structures Assessment Research Center (ISARC) funded by the Ministry of Land, Transport, and Maritime Affairs (MLTM), Korea. The authors gratefully acknowledge this support.

\section{References}

1. Glanvile, J. and Nevile, A., Prediction of Concrete Durability, Proceedings of STATS 21st Anniversary Conference, E\&FN SPON, 1995, pp. 16 36.

2. Halabe, U. B., Sotoodehnia, A., Maser, K. R., and Kausel, E. A., "Modeling the Electromagnetic Properties of Concrete," $A C I$ Material Journal, Vol. 90, 1993, pp. 552 563.

3. Rhim, H. C. and Buyukozturk, O., "Electromagnetic Properties of Concrete at Microwave Frequency Range," ACI Material Journal, Vol. 95, 1998, pp. 262 271.

4. Neithalath, N., "Extracting the Performance Prediction of Enhanced Porosity Concrete from Electrical Conductivity Spectra," Cement and Concrete Research, Vol. 37, 2007, pp. 796 804.

5. Soutsos, M. N., Bungey, J. H., Millard, S. G., Shaw, M. R., and Patterson, A., "Dielectric Properties of Concrete and Their Influence on Radar Testing," NDT\&E International, Vol. 34, 2001, pp. 419 425.

6. Gonen, T. and Yazicioglu, S., "The Influence of Compaction Pores on Sorptivity and Carbonation of Concrete," Construction and Building Material, Vol. 21, 2007, pp. 1040 1045.

7. Metha, K. and Monteiro, P. J. M., Concrete: Structure, Properties, and Materials, Vol. 2, Prentice Hall, New Jersy, 1993.

8. Neville, A., Properties of Concrete, Longman, 1996 (revised).

9. Song, H. W., Kwon, S. J., Byun, K. J., and Park, C. K., "Predicting Carbonation in Early-Aged Concrete," Cement and Concrete Research, Vol. 36, 2006, pp. 979 989.

10. Song, H. W., Kwon, S. J., Byun, K. J., and Park, C. K., "A Study on Analytical Technique of Chloride Diffusion Considering Characteristics of Mixture Design for High Performance Concrete Using Mineral Admixture," Journal of KSCE, Vol. 25, 2005, pp. 213 223 (in Korean).

11. Song, H. W. and Kwon, S. J., "Permeability Characteristics of Carbonated Concrete Considering Capillary Pore Structure," Cement and Concrete Research, Vol. 37, 2007, pp. 909 915.

12. Wittmann, F. H., "Micro Wave Absorption of Hardened Cement Paste," Cement and Concrete Research, Vol. 5, 1975, pp. $63 \sim 71$.

13. Chrisp, T. M., McCarter, W. J., Starrs, G., Basheer, P. A. M., and Blewett, J., " Depth-Related Variation in Conductivity to Study Cover Zone Concrete during Wetting and Drying," Cement and Concrete Research, Vol. 24, 2002, pp. 415 426.

14. Rhim, H. C. and Jeong, S. H., "Measurement of Electromagnetic Properties of Concrete for Nondestructive Testing," Journal of KCI, Vol. 12, 2000, pp. 115 123 (in Korean). 
15. Shi, C., Stegemann, J. A., and Caldwell, E. J., "Effect of Supplementary Cementing Materials on The Specific Conductivity of Pore Solution and Its Implications on The Rapid Chloride Permeability Test (AASHTO T277 and ASTM C1202) Results," ACI Material Journal, Vol. 95, 1998, 389 394.

16. McCarter, W. J., Starrs, G., and Chrisp, T. M., "Electrical Conductivity, Diffusion, and Permeability of Portland CementBased Mortar," Cement and Concrete Research, Vol. 30, 2000, pp. 1395 1400.

17. Garboczi, E. J., Schwartz, L. M., and Bentz, D. P., "Modeling the D.C. Electrical Conductivity of Mortar," Material Research Symposium, Proceedings, Vol. 370, 1995, pp. 429 436.

18. McCarter, W. J., Chrisp, T. M., Starrs, G., and Blewett, J., "Characterization and Monitoring of Cement-Based Systems Using Intrinsic Electrical Property Measurements," Cement and Concrete Research, Vol. 33, 2003, pp. 197 206.

19. McCarter, W. J., Chrisp, T. M., and Starrs, G., "The Early Hydration of Alkali-Activated Slag : Developments in Monitoring Techniques," Cement and Concrete Composites, Vol. 21, 1999, pp. 277 283.

20. McCarter, W. J., Starrs, G., and Chrisp, T. M., "Immittance Spectra for Portland Cement/Fly Ash-Based Binders during Early Hydration," Cement and Concrete Research, Vol. 29, 1999, pp. 377 387.

21. McCarter, W. J., Starrs, G., and Chrisp, T. M., "The Complex Impedance Response of Fly-Ash Cement Revisited," Cement and Concrete Research, Vol. 34, 2004, pp. 1837 1843.

22. Rhim, H. C., "Condition Monitoring of Deteriorating Concrete Dams Using Radar," Cement and Concrete Research, Vol. 31, 2001, pp. 363 373.

23. Halabe, U. B., Condition Assessment of Reinforced Concrete Structures Using Electromagnetic Waves, Doctoral thesis, Department of Civil Eng. MIT, Cambridge, 1990.

24. Roddis, W. M. K., Concrete Bridge Deck Assessment Using Thermography and Radar, Master's thesis, Department of Civil Eng. MIT, Cambridge, 1987.

25. Feng, S. and Sen, P. N., "Geometrical Model of Conductive and Dielectric Properties of Partially Saturated Rocks," Journal of Applied Physics, Vol. 58, 1985, pp.3236 3243.

26. Rhim, H. C., Kim, Y. J., Feng, M. Q., Woo, S. K., and Song, Y. C., "Properties of Concrete and Fiber Reinforced Poly- mer for Nondestructive Testing," Proc. of The US-Korea Joint Workshop on Smart Structures Technologies, Seoul, Korea, September 2 4, 2004.

27. Feng, M. Q., Kim, Y. J., and De Flaviis, F. D., "Use of Microwaves for Damage Detection of FRP-wrapped Concrete Structures," Journal of Engineering and Mechanics, ASCE, Vol. 128, 2001, pp. 172 183.

28. Kim, Y. J., Jofre, L., De Flaviis, F. D., and Feng, M. Q., "Microwave Reflection Tomography Array for Damage Detection of Concrete Structures," Proc. of IEEE MTT-S Int. Microwave Symposium, Digest, Seattle, WA, 2002, June 2 7, pp. 651 654.

29. Rhim, H. C., Kim, Y. J., Feng, M. Q., Woo, S. K., and Song, Y. C, "Measurements of Electromagnetic Properties of Concrete and Fiber Reinforced Polymer for Nondestructive Testing," US-Korea Joint Seminar/Workshop on Smart Structures Technologies, Sheraton Walker Hill Hotel, Seoul, Korea, September 2, 2004.

30. Feng, M. Q., Kim, Y. J., and Park, K., "Real-Time and Hand-Held Microwave NDE Technology for Inspection of FRPWrapped Concrete Structures," FRP International-The Official Newsletter of the International Institute for FRP in Construction, Vol. 3, 2006, pp. 2 5.

31. Nyshadham, A., Sibbad, C. L., and Stuchly, S. S., "Permittivity Measurement using Open-Ended Sensor and Reference Liquid Calibration-An Uncertainty Analysis," IEEE Transactions on Microwave Theory and Techniques, MTT-40, Vol. 1992, pp. $305 \sim 313$.

32. Korean Standard, Method of Test for Compressive Strength of Concrete, KSF 2405, 2005.

33. Maekawa, K., Chaube, R., and Kishi, T., Modeling of Concrete Performance, E\&FN SPON, 1999.

34. Ishida, T., Maekawa, K., and Kishi, T., "Enhanced Modeling of Moisture Equilibrium and Transport in Cementitious Materials under Arbitrary Temperature and Relative Humidity History," Cement and Concrete Research, Vol. 37, 2007, pp. 565 578.

35. Kwon, S. J., Feng, M. Q., and Na, U. J., "An Experimental Study on Characteristics of Averaged Electromagnetic Propertiies considering Moisture Changes in Cement Mortar," Journal of KCI, Vol. 21, No. 2, 2009, pp. 199 207 (in Korean). 